\title{
Witnessable quantifiers license type-e meaning: Evidence from contrastive topic, equatives and supplements *
}

\author{
Noah Constant \\ University of Massachusetts, Amherst
}

\begin{abstract}
This paper presents three novel ways of testing which plural quantificational phrases can denote individuals (type e). Specifically, it is argued that only type-e expressions can (i) be marked as a contrastive topic in a discourse contrasting individuals, (ii) be equated with another type-e expression in an equative frame, and (iii) anchor supplementing material. The main empirical finding is that the class of quantifiers allowing type-e nominal denotations is larger than assumed on classic accounts like Reinhart 1997. Furthermore, this class is characterizable in semantic terms. The quantifiers that give rise to type-e meanings are WITNESSABLE in the sense of entailing the existence of an individual satisfying both their restrictor and their nuclear scope.
\end{abstract}

Keywords: quantifier, choice function, exceptional wide scope, wide-scope indefinite, contrastive topic, equative, supplement

\section{Introduction}

Reinhart's (1997) choice-functional account of indefinites holds that certain nominals like 'some cats' can denote individuals (type e), while other nominals like 'most cats' and 'few cats' only have traditional generalized quantifier (GQ) denotations of type $\langle\langle e, t\rangle, t\rangle$. While this analysis was designed to capture facts about which quantificational expressions are able to take exceptional wide scope, the type distinction Reinhart posits has other consequences as well. Three of these consequences will be of particular interest to us here. First, building on arguments from Rooth (2005), we find that being individual-denoting is a prerequisite for an expression to serve as a contrastive topic in a discourse that answers questions about contrasting individuals. Second, we will see that only a type-e expression can be equated with another type-e expression in an equative construction. Finally, individuals, but not GQs,

* I am grateful to the following people for discussion: Seth Cable, Donka Farkas, Kai von Fintel, Anastasia Giannakidou, Martin Hackl, Irene Heim, Ezra Keshet, Angelika Kratzer, Barbara Partee, Chris Potts, Roger Schwarzschild, Yasutada Sudo, Anna Szabolcsi, and audiences at MIT's LFRG and SALT 22. Special thanks are due to Seth Cable, Ezra Keshet and Angelika Kratzer for detailed comments on a draft. 
Witnessable quantifiers license type-e meaning

can stand as anchors for supplementing material, including nominal appositions and non-restrictive relatives.

When we apply these distributional diagnostics as tests for individual-denoting meaning, the surprising result is that the class of type-e quantificational DPs looks to be larger than we had assumed. Beyond classic wide-scope indefinites like 'some cats' and 'three cats', this class contains DPs with strong quantifiers like 'most cats', and modified numeral expressions like 'more than five cats'. The semantic property unifying all of these plural nominals is that they are what I will call WITNESSABLEthey entail the existence of an individual satisfying both their restrictor and their nuclear scope, as in (1). ${ }^{1}$ To summarize the main claim then, while classic accounts like Reinhart 1997 hold that only the quantifiers in (2a) can denote individuals, I propose that those in (2b) also allow this possibility.

(1) A determiner Det is Witness Able iff $\operatorname{Det}(P)(Q) \rightarrow \exists x: P(x) \wedge Q(x)$

(2) a. some, a, three, several, many, a few (witnessable)

b. most, all, more than 3 , at least 3 , exactly 3 , half (witnessable)

c. few, no, less than 3 , not many

(non-witnessable)

We should be clear at the outset that nothing prevents one from implementing a choice-functional (type-e) analysis of any of these quantifiers, with the possible exception of no. For example few could be given a property-modifying cardinality meaning as in (3), allowing the meaning of [few cats] $]_{\mathrm{NP}}$ to combine with a covert choice function variable to produce a specific small plurality of cats. The issue at stake is just which natural language quantifiers actually allow such choice-functional interpretations, and whether any principled explanation underlies this division.

$$
\llbracket \text { few } \rrbracket \stackrel{?}{=} \lambda P_{\langle\mathrm{e}, \mathrm{t}\rangle} \lambda x_{\mathrm{e}}[P(x) \wedge|\operatorname{Atoms}(x)| \ll|\{y: P(y)\}|]
$$

As it happens, Reinhart (1997: 386), in looking for a semantic principle underlying this division, considers a property similar to the sense of witnessable used here, ${ }^{2}$ but rejects it on the grounds that more than three and most supposely lack type-e readings (based primarily on their scopal behavior). Thus, my goal here is to show that an intuitively plausible account of the type division in terms of witnesses is in fact tenable after all.

1 Following Horn (1972: §2, 2006), the decreasing quantifiers few, not many and so on generate scalar implicatures that at least one individual satisfies their nuclear scope. So for example, on hearing "Few students passed", we will often infer that at least one student passed. If this "more than none" component were part of the truth-conditional meaning, these quantifiers would count as witnessable. However, this cannot be the right analysis, since the extra meaning is cancelable. That is, without contradicting myself, I can say "Few students passed. In fact, none did."

2 For Reinhart (building on Szabolcsi 1995, 1997), the relevant quantifiers are those that allow assessment by checking just one minimal witness set of the GQ, where a witness set is any set in the 
The main three sections of the paper present the novel diagnostics. Section $\S 2$ looks at contrastive topic marked quantifiers, and motivates the basic choice function account. Sections $\S 3$ and $\S 4$ introduce the equative and supplement tests, which confirm the results from contrastive topic. Section $\$ 5$ concludes with a note on the scope-taking abilities of the various types of quantifier phrase.

\section{Contrastive Topic Quantifiers}

This section shows how contrastive topic (CT) intonation can be used to diagnose which quantifier phrases can denote individuals. What we find by applying this diagnostic is that all and only witnessable quantifiers allow type-e meaning. I postpone the application of the diagnostic to the end of the section. The first step will be to show that CT-marked quantifiers are incompatible with GQ semantics (although we will see one exception). This point is to my knowledge first discussed by Rooth (2005), and I review and expand upon his arguments.

\subsection{Background on Contrastive Topic}

In English, contrastive topics are realized with a distinctive intonation pattern (Büring 2003). We see a typical example in (4), where the subject is pronounced with a contrastive topic (CT) contour, and the object is pronounced with a falling focus (F) contour. In the ToBI tradition (Silverman et al. 1992), the sentence is parsed as two intonational phrases, the first with a rising accent and a rising boundary tone $\left(\mathrm{L}+\mathrm{H}^{*} \mathrm{~L}-\mathrm{H} \%\right)$, and the second with a falling accent and falling boundary $\left(\mathrm{H}^{*} \mathrm{~L}-\mathrm{L} \%\right)$. Here and throughout, I mark sentence-level stresses with CAPITALS, and relevant rising intonational breaks with '...'.

(4) A: What about Persephone and Antonio? What did THEY eat?

B: PERSEPHONE ... ate the GAZPACHO.
$\mathrm{L}+\mathrm{H}^{*} \mathrm{~L}-\mathrm{H} \%$
$\mathrm{H}^{*} \mathrm{~L}-\mathrm{L} \%$

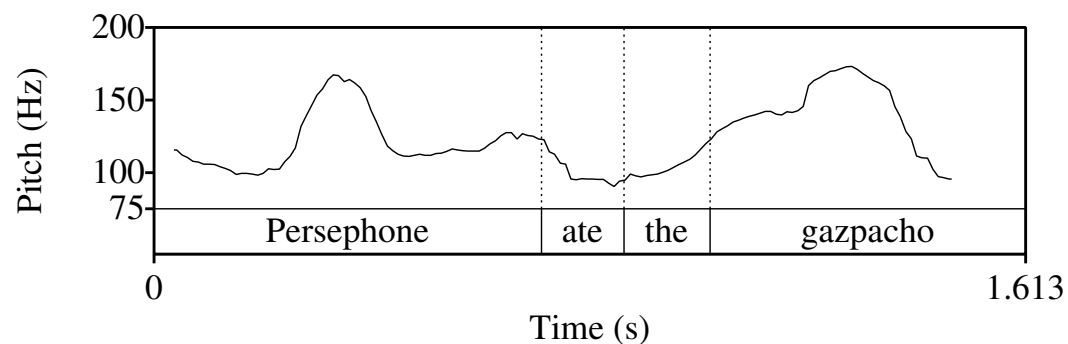

denotation of the GQ that is also a subset of its live-on set (Barwise \& Cooper 1981). While ruling in most and more than three, this definition would rule out quantifiers like exactly three, which is witnessable in my sense, but cannot be assessed by checking just one minimal witness set. 
Intuitively, the intonation in (4) marks that the speaker is answering a question about what Persephone ate, but has left unaddressed a salient issue about what someone else ate-in this case, Antonio. To model the contrasting alternatives evoked by the intonation, modern analyses of contrastive topic have been developed within Rooth's (1985) alternative-based semantics for focus (Büring 1997, 2003; Steedman 2008, Wagner 2008, 2012; Tomioka 2010; Constant in prep.).

At the heart of Rooth's interpretation system is the idea that a focused phrase generates alternatives of the same semantic type as the phrase itself. Individualdenoting expressions give rise to individual-denoting alternatives, properties generate property alternatives, and so on. However, this fundamental principle of Rooth's framework runs us into trouble when we look at CT-marked quantifiers.

\subsection{The Problem for Classic GQ Accounts}

Prominent theories of contrastive topic have either treated nominals containing CTmarked quantifiers as having standard GQ semantics, as in Büring 1997, or else don't take a stand on the issue (e.g. Büring 2003, Tomioka 2010, Wagner 2012). However, Rooth (2005) observes that the GQ account as laid out by Büring (1997) is not sufficient. The basic problem is that if a quantificational phrase like 'some cat' is interpreted as a generalized quantifier of type $\langle\langle\mathrm{e}, \mathrm{t}\rangle, \mathrm{t}\rangle$, then we should expect that when such a phrase contains contrastive topic marking, the contrasting alternatives will be elements of the same type, namely other generalized quantifiers. However what we find is that quantifiers marked as contrastive topics set up contrasts with individuals, not with GQ meanings.

I discuss four manifestations of this basic problem, two already mentioned by Rooth and two additional ones. For the sake of illustration, I limit the discussion to Büring's (2003) implementation of CT meaning, although the problem extends both to earlier accounts like Büring 1997, and to more recent theories like those of Tomioka (2010) and Wagner (2012). To be clear, the problem to be discussed is not with these theories themselves, but with the predictions the theories make if we assume (with Büring 1997) that when some and most are CT-marked their interpretations are as traditional quantifiers of type $\langle\langle\mathrm{e}, \mathrm{t}\rangle,\langle\langle\mathrm{e}, \mathrm{t}\rangle, \mathrm{t}\rangle\rangle$.

Büring (2003) predicts that an utterance with CT is always a partial answer, in the sense of answering just one among a set of two or more salient questions making up a larger issue-in Roberts' (1996) terms, this set of questions is a DISCOURSE STRATEGY. Furthermore, the form of the discourse strategy is constrained by the placement of CT- and F- marking on the utterance. Büring's CT-CONGRUENCE condition requires that the strategy contain at least two questions within the CTVALUE of the CT-marked utterance, which is calculated by (loosely speaking) substituting different values for the CT- and F- marked constituents. Thus, the 
CT-value $\llbracket \cdot \rrbracket^{c t}$ of the response in (5) will be the set shown in (6), and CT-Congruence will be satisfied since at least two implicit questions of the form Where does $X$ live appear in the context.

(5) A: Where do the grads live?

B: $[\text { FRED }]_{\text {CT }} \ldots$ lives $[\text { in AMHERST }]_{F}$.

$$
\mathrm{L}+\mathrm{H} * \mathrm{~L}-\mathrm{H} \% \quad \mathrm{H}^{*} \mathrm{~L}-\mathrm{L} \%
$$

$$
\begin{aligned}
& \llbracket(5) \rrbracket^{c t}=\left\{\begin{array}{c}
\{\text { Fred lives in Amherst, Fred lives in Northampton, } . .\}, \\
\{\text { Mary lives in Amherst, Mary lives in Northampton, ... }\}, \\
\ldots
\end{array}\right\} \\
& =\{\text { Where does Fred live?, Where does Mary live } ?, \ldots\}
\end{aligned}
$$

On Büring's (2003) theory, B's response in (5) is analyzed as answering the implicit question Where does Fred live, which is a sub-question of an overarching issue of where both Fred and particular other people live. And intuitively, this is correct. However, as Rooth (2005) points out, the account becomes less plausible when applied to CT-marked quantifiers. ${ }^{3}$ While the response in (7) is clearly a partial answer to A's question, it doesn't seem to be answering an implicit question Where do some grads live, as Büring's theory would predict. Furthermore, in this case, it seems unlikely that the discourse contains contrasting questions within the CT-value shown in (8), where some has been switched with other quantificational determiners. Intuitively 'SOME grads' is contrasting not with GQ-denoting alternatives like 'many grads', but rather with individual-denoting alternatives like 'the other grads'.
A: Where do the grads live?
B: $[\text { SOME }]_{\text {CT }}$ grads ... live [in AMHERST $]_{\mathrm{F}}$.

$$
\mathrm{L}+\mathrm{H}^{*} \quad \mathrm{~L}-\mathrm{H} \% \quad \mathrm{H}^{*} \mathrm{~L}-\mathrm{L} \%
$$

(8) $\llbracket(7) \rrbracket^{c t}=\{$ Where do some grads live?, Where do many grads live?, .. $\}$

Beyond the intuitive implausibility of contrasting quantifier denotations, Rooth observes a problem in terms of the implicatures predicted. In general, when contrastive topic marks the answer to a sub-question (even an implicit one), a conversational implicature is generated to the effect that the marked utterance is a complete answer to that sub-question. For example, (9) implicates that Manny is the only person who Anna danced with. By the same token, if (7) answers the implicit question Where do some grads live, we predict an implicature that Amherst is the only place that has some grads living there. However there seems to be no implicature of this sort.

3 With Rooth and Büring, I assume that examples like (7) involve narrow CT-marking on the quantifier itself, as opposed to marking the entire nominal constituent. However even if one were able to motivate an analysis of (7) as [SOME grads $]_{\mathrm{CT}}$, the problems I discuss would remain. 
Witnessable quantifiers license type-e meaning

(9) A: Who danced with who?

B: $[\text { ANNA }]_{\text {CT }} \ldots$ danced with $[\text { MANNY }]_{F}$.

Rooth 2005: (32)

Beyond the problems Rooth mentions, I would like to raise two additional obstacles to treating CT quantifiers in terms of contrasting GQ meanings. First, as (10) shows, we have the possibility of contrasting two instances of the same quantifier. The problem here is that, according to Büring's CT-Congruence condition, each of B's responses should mark a contrast between the sub-question being answered (Where do some grads live) and some other question in the discourse, where some is replaced with a differing alternative of type $\langle\langle\mathrm{e}, \mathrm{t}\rangle,\langle\langle\mathrm{e}, \mathrm{t}\rangle, \mathrm{t}\rangle\rangle$ like most or few. However, in this dialogue, no additional sub-questions are implied. That is, B's two responses may exhaust the grad students in question-so none of them live anywhere but these two towns. In this case, each occurrence of some simply contrasts with the other, rather than contrasting with some implicit differing quantifier.

(10) A: Where do the grads live?

B: $[\text { SOME }]_{\text {CT }}$ of them ... live $[\text { in AMHERST }]_{\mathrm{F}}$. And $[\text { SOME }]_{\text {CT }}$ of them ... live $[\text { in NORTHAMPTON }]_{F}$.

Finally, we reach perhaps the most striking puzzle for the GQ account. If sentences like (7) are interpreted by generating traditional quantifier alternatives to some, then we should equally well be able to generate alternatives to a quantifier like few. However few in fact strongly resists CT-marking, as in (11). Furthermore, (12) shows that it is nothing more than the intonational pattern ruling the sentence out. If the $\mathrm{CT}$ and $\mathrm{F}$ accents are reversed, the sentence is acceptable, and marks a strategy of questions of the form For each place, how many of the grads live there. ${ }^{4}$

(11) A: Where do the grads live?

B: \#[FEW $]_{\mathrm{CT}}$ of them ... live $[\text { in AMHERST }]_{\mathrm{F}}$.
$\mathrm{L}+\mathrm{H}^{*}$
$\mathrm{L}-\mathrm{H} \%$
$\mathrm{H}^{*} \mathrm{~L}-\mathrm{L} \%$

(12) A: Where do the grads live?

B: $[\text { FEW }]_{\mathrm{F}}$ of them live $[\text { in AMHERST }]_{\mathrm{CT}} \ldots$ $\mathrm{H}^{*} \quad \mathrm{~L}-\mathrm{L}+\mathrm{H}^{*} \mathrm{~L}-\mathrm{H} \%$

\subsection{The Choice-Functional Account}

The solution Rooth (2005) puts forward is to treat the problematic CT-marked phrases like 'SOME cat(s)' using choice function variables, rather than classic quantifier denotations. Suppose some denotes a choice function variable-a function of type $\langle\langle\mathrm{e}, \mathrm{t}\rangle, \mathrm{e}\rangle$ that given a property as input, returns some individual who has that property.

4 The dialogue in (12) is more natural if the decision to sort by places instead of people is made explicit-for example, if A's question is followed up with "Do any live in AMHERST?" Note that this modification does not save (11). 
Thus, 'some cat' and 'some cats' are of type e, and denote a particular cat and a particular plurality of cats respectively. When we adopt this analysis, the alternatives generated by '[SOME $]_{\mathrm{CT}}$ cats' are computed by substituting different choice functions in the position of the CT-marked some. Combining these with the restrictor cats, we produce contrasting pluralities of cats. ${ }^{5}$

This approach immediately addresses our four concerns from above. If 'some grads' denotes a specific plural individual, then we expect (7) to answer an implicit question about where a particular group of grads lives. This seems to be exactly what (7) does, and this time the expected implicature that the answer resolves the sub-question goes through. Furthermore, since different instances of some can stand for different choice function variables, we have an explanation for why some and some are able to contrast in (10). Finally, from Reinhart (1997), we know that quantifiers like few lack choice-functional interpretations. Thus, (11) only has the standard GQ reading, and if we maintain — as Rooth seems to - that CT is simply unable to contrast quantifiers of this type, then the sentence will be ruled out.

In a moment, we will see a challenge for this account, relating to the question of which quantifiers are compatible with choice function interpretations. But first, let me address a caveat, concerning the ability of true GQs to be CT-marked. In most cases, it is accurate to say that $f e w$ fails as a contrastive topic. This failure makes sense on the view that nominals with few are robustly GQ-denoting, given some reasonable assumptions about how we tend to structure discourse. Specifically, let's say that for cognitive reasons, we avoid breaking up large issues into sub-issues sorted by proportions as opposed to individuals. That is, while it's easy to ask a subquestion about an individual (What about FRED? Where does HE live?), it's hard to treat proportions in the same way (What about FEW? Where do FEW students live?). However this is not to say that such a discourse is impossible. The following context licenses a CT-marked use of $f e w$, precisely because we are contrasting proportions: ${ }^{6}$

5 Rooth suggests that quantifiers like some and many denote choice functions directly, but does not propose specific denotations. One approach is to encode the cardinality component of the quantifiers' meaning as a presuppositional modifier to a choice function variable, and to let quantificational determiners spell out the entire [modifier+variable] complex (cf. gender marking on pronouns). Note that if we adopted Reinhart's proposal, where a silent choice function variable occupies the specifier of DP, then the structure [f [many cats] $]_{D P}$ wouldn't contain an appropriate constituent to be F-marked. Crucially, we want the alternatives to vary both the quantifier and the CF variable, while leaving the restrictor constant. To achieve this, while keeping the CF variable and the quantifier distinct at LF, we could use the structure [[f many $]_{F}$ cats $]$. On this analysis, the quantifiers in individual-denoting DPs are choice function modifiers that add a presuppositional restriction on the cardinality of the entity returned by the function. For example, $\llbracket$ many $\rrbracket=\lambda f_{\langle\langle\mathrm{e}, \mathrm{t}\rangle, \mathrm{e}\rangle} \lambda P_{\langle\mathrm{e}, \mathrm{t}\rangle}[f(P)$ if $|\operatorname{Atoms}(f(P))|>5$, otherwise undefined]. At the moment, I see no way of determining whether many spells out this modifier alone, or spells out the entire complex structure including the modifier and CF variable.

6 While I claim there is a moderate cognitive difficulty in using a classical quantifier denotation as a contrastive topic, I do not wish to suggest that quantifier meanings resist being marked for contrast in 
Witnessable quantifiers license type-e meaning

(13) Context: A is trying to figure out how hard each problem is on an exam she has written. As an experiment, she asks B to have his students take the exam, to see how they do. After B has graded the exams, A asks...

A: Okay, first tell me, which problems did ALL the students solve?

B: ALL the students solved problems one and six.

A: And which problems did MOsT of them solve?

B: Most of them solved problems two and five.

A: And which problems did FEW of them solve?

B: $[\text { FEW }]_{\mathrm{CT}}$ of them ... solved $[\text { problems three and FOUR }]_{\mathrm{F}}$. $\mathrm{L}+\mathrm{H}^{*} \mathrm{~L}-\mathrm{H} \% \quad \mathrm{H}^{*} \mathrm{~L}-\mathrm{L} \%$

Unlike Rooth's examples, in this case, we really are directly answering a sub-question containing a GQ, and in fact the sub-question appears explicitly in the discourse. Furthermore, in this case, the implicature of a complete answer is plausible. That is, B could reasonably be taken to imply that problems three and four are the only ones that few students solved.

To wrap up our caveat, it is not true (as Rooth's examples in isolation might suggest) that GQ denotations are fundamentally incompatible with CT meaning. Rather, CT-marking on a quantifier in a GQ-denoting phrase will require a discourse that "sorts by proportions", and these are hard to come by. The basic fact that we need to capture, then, is that CT-marked quantifiers like some do not necessarily set up proportional contrasts, and thus do not require this sort of unusual supporting context. The proposal on the table is that they are free of this requirement by virtue of having a choice-functional interpretation.

\subsection{Which Quantifiers Have CF Interpretations?}

If this proposal is correct, then we expect all and only the quantifiers that allow CF interpretations to be compatible with CT marking in a context like (14) below. Happily, the quantifiers that traditionally allow CF interpretations are all licensed in this frame. Furthermore, many of the quantifiers that are generally assumed to lack CF interpretations (e.g. $f e w$ ) are illicit, as expected. However there is a serious concern. We find CT is licensed on a range of quantifiers that are widely viewed as lacking CF interpretations, including most, half, more than $N$ and exactly $N^{7}$

general. In particular, we find no corresponding difficultly using a quantifier as contrastive focus. For example, if I ask how many students passed, you can answer "FEW of them passed." Intuitively, posing a question that asks you to choose the correct proportion out of a set of proportions is natural, whereas posing a strategy of sub-questions each asking about a different proportion is unusual.

7 The reader may note that all fails as a contrastive topic in (14), despite being witnessable (assuming all presupposes a non-empty domain). This is not because 'all of the grads' fails to denote type e; we will see in the next section that it has this ability. Rather, all is unable to stand as CT in (14) because 
(14) A: Where do the grads live?

$\mathrm{B}:\left[\frac{{ }_{\mathrm{L}+\mathrm{H}^{*}}}{]_{\mathrm{CT}}}\right.$ (of the) grads ... live $[\text { in AMHERST }]_{\mathrm{F}}$.

$$
\left\{\begin{array}{c}
\text { Some } \mid \text { Ten } \mid \text { MAny } \mid \text { SEVEral } \mid \text { A FEW } \\
\text { Most } \mid \text { HALf } \mid \text { More than TEN } \mid \text { Exactly TEN } \\
\text { \#FEW } \mid \text { \#NONE } \mid \text { \#Not MAny } \mid \text { \#Less than TEN }
\end{array}\right\}
$$

The simplest explanation for these facts, and the one I pursue here, is to say that all the licit quantifiers in (14) can get choice-functional interpretations (although this is not their only interpretation). This goes against the traditional wisdom on the matter, which is grounded in facts about the scope-taking abilities of the different quantifiers. We'll return to the scope facts briefly in section $\S 5$. The more striking fact, though, and the focus of sections $\S 3$ and $\S 4$ is that a range of further diagnostics call for the same set of quantifiers - the witnessable ones - to be of type e.

To wrap up the discussion of CT as a diagnostic for quantifier type, I'd like to present two examples that attest to the range of cases in which the diagnostic can apply. In (15-16), we find that the pattern from above extends to adverbial and adjectival quantifiers, in the temporal and modal domains. As with $f e w$, the quantifiers that resist $\mathrm{CT}$ are downward entailing, and plausibly non-witnessable: ${ }^{8}$

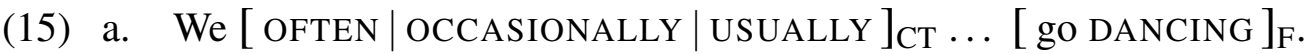

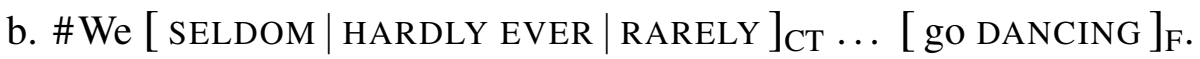

$$
\begin{aligned}
& \text { a. It's [ LIKELY } \left.\mid \text { PROBABLE } \mid \text { POSSIBLE }]_{\mathrm{CT}} \ldots \text { that he'll [ WIN }\right]_{\mathrm{F}} \text {. } \\
& \text { b. \#It's [ UNLIKELY } \mid \text { IMPROBABLE } \mid \text { DOUBTFUL }]_{\mathrm{CT}} \ldots \text { that he'll }[\mathrm{WIN}]_{\mathrm{F}} \text {. }
\end{aligned}
$$

\section{Equatives}

This section presents new evidence from equatives that witnessable quantifier phrases like 'most cats' can denote type e, while non-witnessables like 'few cats' cannot.

\subsection{The Equative Diagnostic and How it Works}

Equatives are copular constructions that equate two individual-denoting expressions. In the following frame, if the object is able to denote a plurality, the sentence is a

the CT-marked utterance would completely resolve the issue at hand, conflicting with the partial answer semantics of CT. See Büring (1997) for more detailed discussion of this type of infelicity.

8 If the adverbials in (15) quantify over times (following Kamp 1971 and Partee 1973) or situations (following Heim 1990 and von Fintel 1994), and the modals in (16) over possible worlds (building on Kripke 1959, 1963, and others) then we can imagine treatments of often and likely as witnessable, in the sense of entailing the existence of a time, situation, or world where the nuclear scope holds. Seldom and unlikely would be non-witnessable, since they don't entail any such existence. 
Witnessable quantifiers license type-e meaning

well-formed equation of two pluralities. On the other hand, if the object can only denote a GQ, then the sentence will be ill-formed, for reasons we will see shortly. Remarkably, this frame makes the same cut across quantifiers that we saw in the previous section.

(17) Those people standing over there are of my best students.

$$
\left\{\begin{array}{c}
\text { some }|20| \text { many } \mid \text { several } \mid \text { a few } \\
\text { most } \mid \text { all } \mid \text { more than } 20 \mid \text { exactly } 20 \mid \text { half } \\
* \text { few } \mid * \text { none } \mid * \text { not many } \mid \text { ??less than } 20
\end{array}\right\}
$$

What goes wrong if the object in (17) denotes a GQ? There are a variety of answers, depending on how we aim to interpret the sentence compositionally. I discuss here four (non-)options for interpretation, each of which will result in either a degenerate meaning or a type mismatch. Of course, other mechanisms for interpreting these structures could be devised to sidestep these problems. But the point is that such mechanisms cannot exist, or else the infelicitous forms in (17) would be acceptable.

At the root of it, the problem is in how the object composes with the rest of the sentence. If the copula is taken to be inert, the GQ object can't compose directly with the individual-denoting subject. On the other hand, if we treat $b e$ as a two-place predicate, this can't combine with the GQ either. One standard approach to avoiding this apparent type mismatch is to raise the GQ via quantifier raising (QR), leaving a type e trace below. However, in our example, the property that would result from QR can never be satisfied by atomic individuals. Specifically, the property that would end up as the nuclear scope of $f e w$ is the property of being those people standing over there. Since few quantifies over atoms, this property is never satisfiable, and the truth conditions are vacuous.

In (18), we see a more explicit rendering of the problem with QR. Given the type $\langle\langle e, t\rangle,\langle\langle e, t\rangle, t\rangle\rangle$ quantifier denotation for few in (18a), the GQ 'few of my best students' will be uninterpretable in object position, and will be forced to undergo QR to a position above the subject, as in (18b). However, the resulting truth conditions in (18c) are tautological, given that no atomic individual can be a plurality. By contrast, (19a) shows a choice-function-compatible property-modifying denotation for most. Since the meaning of 'most of my best students' can combine with the null choice function variable $f_{3}$, the expression can be interpreted in situ as type e, as in (19b). The truth conditions in (19c) are reasonable, assuming some mechanism for binding of the choice function at the level of discourse. ${ }^{9}$

9 There are various approaches here, and the data so far don't provide evidence for one over another. For Reinhart (1997) and Winter (1997), the choice function variable is bound existentially. For Kratzer (1998, 2003), choice function variables receive their value directly from the context of utterance (though a speaker need not know which choice function she is referring to). In the next section, we will see one argument in favor of Kratzer's approach. 
a. $\llbracket$ few $\rrbracket=\lambda P_{\langle\mathrm{e}, \mathrm{t}\rangle} \lambda Q_{\langle\mathrm{e}, \mathrm{t}\rangle}$

$$
|\{x: \operatorname{atom}(x) \wedge P(x) \wedge Q(x)\}| \ll|\{x: \operatorname{atom}(x) \wedge P(x)\}|
$$

b. $[\text { few of my best students }]_{\mathrm{DP}}\left[\lambda_{3} \text { [ those people }\right]_{\mathrm{DP}}$ are $\left.t_{3}\right]_{\mathrm{IP}}$

c. $\mid\{x: \operatorname{atom}(x) \wedge \operatorname{best}(x) \wedge$ is-those-people $(x)\}|\ll|\{x: \operatorname{atom}(x) \wedge \operatorname{best}(x)\} \mid$

"Among the atomic individuals that have the property of being one of my best students, few have the property of being those people over there."

$$
\begin{aligned}
& \text { a. } \llbracket \operatorname{most} \rrbracket=\lambda P_{\langle\mathrm{e}, \mathrm{t}\rangle} \lambda x_{\mathrm{e}}\left[P(x) \wedge|\operatorname{Atoms}(x)|>\frac{1}{2} \times|\{y: \operatorname{atom}(y) \wedge P(y)\}|\right] \\
& \text { b. }[\text { those people }]_{\mathrm{DP}} \text { are }\left[\mathrm{f}_{3} \text { most of my best students }\right]_{\mathrm{DP}} \\
& \text { c. The unique } x_{\mathrm{e}} \text { s.t. } x \text { is "those people standing over there" } \\
& \quad=\mathrm{f}_{3}\left(\lambda x_{\mathrm{e}}\left[\operatorname{best}(x) \wedge|\operatorname{Atoms}(x)|>\frac{1}{2} \times|\{y: \operatorname{atom}(y) \wedge \operatorname{best}(y)\}|\right]\right)
\end{aligned}
$$

"The plurality picked out by 'those people standing over there' is the same as the plurality returned by the choice function $f_{3}$ when applied to the property of being a majority of my best students."

Given the problem for QR, how else might we resolve the type conflict? With the technology of Partee (1987), three type-shifting approaches present themselves. First, we could shift the subject from an individual to a property with Partee's 'ident' operation, as in (20a). Second, we could shift the GQ to a property with Montague's (1973) BE operator in (20b). Finally, we could shift the GQ to an individual with Partee's 'lower' in (20c).

$$
\begin{aligned}
& \text { a. } x_{\mathrm{e}} \rightarrow \lambda y[y=x] \\
& \text { b. } G Q_{\langle\langle\mathrm{e}, \mathrm{t}\rangle, \mathrm{t}\rangle} \rightarrow \lambda x[G Q(\lambda y[y=x])] \\
& \text { c. } G Q_{\langle\langle\mathrm{e}, \mathrm{t}\rangle, \mathrm{t}\rangle} \rightarrow \\
& \quad \text { the generator of principal ultrafilter } G Q \\
& \quad \text { (unique } x \text { s.t. for some set } S: G Q=\text { all supersets of }\{x\} \text { in } S)
\end{aligned}
$$

But while these type shifts offer ways around the type conflict, they don't get us any closer to a reasonable semantics for (17). The first two type-shifting approaches suffer the same problem as QR. We end up requiring that few individuals have the property of being equal to a group. With lowering, the problem is simpler: the shift itself doesn't go through. Standard GQ meanings like few cats are not lowerable, since they are not principal ultrafilters. To be lowerable, a GQ has to be degenerate in the sense of containing all and only the properties that a single individual has-in Winter's (1997) terms, the GQ "corresponds" to a particular individual. ${ }^{10}$ In sum, our attempts at interpreting an object GQ in (17) have failed. If GQs are indeed uninterpretable in this frame, this provides an explanation for the infelicity observed.

10 We could consider redefining 'lower' to map a principal filter onto its generator set (the unique $G$ such that for some set $S$ : $G Q=$ all supersets of $G$ in $S$ ). On Landman's (1989) or Schwarzschild's (1996) 
Witnessable quantifiers license type-e meaning

\subsection{Features of the Equative Diagnostic}

The success of the frame above in getting at the contrast we're looking for derives from a few carefully-selected attributes. It's worth drawing these out to see why other frames fail to make the same slice. First, one may ask what goes wrong if we position the quantificational phrase as the subject instead of the object. That is, if 'most of my best students' can indeed denote a plurality, what's wrong with the following equation of pluralities?

(21) ??Most of my best students are those people standing over there.

I suspect that the problem here is at least partly information-structural. Given that subjects are canonically topics, (17) can serve as a natural answer to the question Who are those people standing over there. By comparison, if the subject in (21) is topical, it would imply the much less natural question Who are most of my best students. Importantly, whatever is wrong with (21) can't be pinned on a general inability of 'most of my best students' to denote a plurality. If this were the source of the problem, we would expect an improvement by switching to an uncontroversially CF-supporting quantifier, but in fact, these are just as bad:

(22) ?? $\{$ Many $\mid$ Several $\}$ of my best students are those people standing over there.

A second feature of the successful equative frame is that the quantifier phrase is partitive. This is crucial to making the cut in question, as we see from the example below, where the object is non-partitive. The judgment marks in (23) reflect my own intuitions, but the precise relative felicities are not important for the present purposes. What is important is that something makes a wide variety of quantifiers unnatural in this context, and that the unnaturalness does not merely hold of those quantifiers that traditionally lack CF readings, but also extends to traditionally CF-compatible quantifiers like many. Thus, infelicity in this frame cannot be taken to demonstrate anything about the semantic type of the quantifier phrase. ${ }^{11}$

approach to plurals, this generator set would directly represent a type-e plurality. (If we followed Link (1983), we'd just define 'lower' to map a principal filter onto the mereological sum of the elements in its generator set.) But even with this extension, a phrase like 'few cats' will not be lowerable unless it is allowed to denote a degenerate GQ that already corresponds to a particular few, presumably by some choice-functional mechanism.

11 A skeptic might at this point contend that the equative diagnostic has only shown that particular quantificational DPs containing partitives can denote type e, and has shown nothing about the type options available to 'most students'. In response, we could turn to examples like "Those people standing over there are ___ contestants qualified to compete", which appear to draw the same split (ignoring half, which requires the partitive), although the judgments are less clear. But ideally we would like to understand exactly why partitives lend support to the type-e readings. I will have to leave this problem to future work. 
(23) Those people standing over there are [ students $]_{\text {DP. }}$

$$
\left\{\begin{array}{c}
\text { some }|20| \text { ?? many } \mid \text { ? several } \mid \text { ? a few } \\
\text { ?? most } \mid \text { ?? all } \mid \text { ? more than } 20 \mid \text { ? exactly } 20 \\
\text { * few } \mid * \text { no } \mid * \text { not many } \mid \text { ?? less than } 20
\end{array}\right\}
$$

A third feature of our successful equative frame is that the subject 'those people standing over there' is individual-denoting. This is not something we can take for granted of definite descriptions or even pronouns. In (24), which appears to contradict our core finding from $\S 2$, I claim that the subjects denote properties-type $\langle e, t\rangle$-following Mikkelsen (2004), and that this is what allows them to compose with GQ-denoting objects. The example does not constitute a challenge to the reasoning behind the equative diagnostic, since it is not an equative at all.

(24) (Who were the winners of last night's elections?)

$\{$ The winners $\mid$ They $\}$ were $\{$ few $\mid$ none $\}$ of the people I would have expected.

The claim that the subjects in (24) denote properties is not far-fetched, given that definite descriptions like 'the winner' and pronouns like it and that are often taken to denote properties in specificational clauses like (25). In fact, Mikkelsen (2004: \$5.2.3) makes use of copular questions asking who instantiates a property as a way of ensuring that an object-focused answer has a property-denoting subject, and this is precisely the type of context in which (24) is most natural.

(25) A: Who is the winner?

B: $\{$ The winner $\mid$ It $\mid$ That $\}$ is Susan.

Perhaps the clearest way to distinguish specificational readings (where the subject is a property) from predicative and equative readings (where the subject is an individual) is by looking at how the subject pronominalizes in tag questions, as in (26), from Mikkelsen (2004: 106). While individual-denoting subjects are resumed by gendered pronouns, property-denoting subjects license neuter pronouns.

a. The tallest girl in the class is Swedish, isn't she?

PREDICATIONAL

b. <Pointing $>$ SHE is Molly Jacobson, isn't she?

EQUATIVE

c. The tallest girl in the class is Molly, isn't it?

SPECIFICATIONAL

It is an inconvenient fact of English, however, that when we turn to plural subjects, this distinction is neutralized. By analogy with (26), we can reasonably assume that they in (27ab) refers back to individual pluralities, while in $(27 \mathrm{c})$ the same pronoun refers back to the property of being the tallest girls in the class. If this is right, then they is not robustly individual-denoting, contra Mikkelsen (2004: 168); rather, they can serve as an anaphor to properties of pluralities. In this case, we cannot use tag questions to directly reveal the semantic type of plural subjects. 
Witnessable quantifiers license type-e meaning

(27) a. The tallest girls in the class are Swedish, aren't they?

b. <Pointing $>$ THEY are Molly and Ana, aren't they?

c. The tallest girls in the class are Molly and Ana, aren't they?

We can however leverage the analogy with singulars to provide indirect evidence as to the types of plural subjects. For example, (28) is a minimal pair with (24) that switches the subject to a singular, and the quantifier to one. The pronoun reveals that this subject is indeed property-denoting, and thus we can infer the same of (24).

(28) The winner was one of the people you expected, wasn't $\{$ it $\mid$ ?? she $\}$ ?

In this light, we can return to our original diagnostic for quantifier phrase type, repeated in condensed form in (29). (I've switched to a gendered noun to make the anaphora judgments clearer.) When we construct a minimal pair in the singular, as in (30), we find that the subject here is robustly individual-denoting. Thus, we are justified both in using (29) as an equative frame to rule out GQ objects, and in disregarding (24) for the same purpose.

(29) Those girls standing over there are $\{$ some $\mid$ most $\mid *$ few $\}$ of my best students.

(30) That girl standing over there is one of your best students, isn't $\{$ she $\mid$ ?? it $\}$ ?

One final point about the equative frame is that for the logic behind the diagnostic to go through, the quantificational phrase itself should not be able to denote a property or quantify over properties. Consider (31), in which the object is not equated with the subject, but instead is predicated of it. Here, there is no requirement that the object denote type e, and non-witnessable quantifiers are licensed.

(31) They say we are rebellious, impulsive, idealistic, irresponsible, inexperienced. In fact, we are $\{$ none $\mid$ few $\mid$ some $\mid$ many $\mid$ most $\mid$ all $\}$ of these things.

To confirm that a copular sentence has or lacks a predicational reading, we can use Mikkelsen's (2004: 164) small clause diagnostic. The fact that (31) can be paraphrased with a small clause structure, as in (32), is evidence that it is predicational. When we run the same test on our original equative frame, as in (33) we get the opposite result. $^{12}$ This confirms that the frame is indeed equative as advertised.

(32) I consider them $\{$ none $\mid$ few $\mid$ some $\mid$ many $\mid$ most $\mid$ all $\}$ of these things.

(33) I consider those people standing over there ?? (to be) \{most $\mid$ more than three $\mid$ half $\mid$ all $\}$ of my best students.

12 The judgments are less clear with some, as in "I consider those people standing over there some of my best students." However the important point is just that the quantifiers at issue here (most, half, all, more than three, and so on) are incompatible with the predicational structure. 


\section{Supplements}

In this section, we find that all and only witnessable quantifier phrases can stand as anchors to supplementing material like nominal appositions and non-restrictive relative clauses. Given that only type-e expressions can anchor supplements, as has been argued previously, the distribution of supplements provides new evidence that all and only witnessable quantifier phrases can denote type e.

\subsection{Background on Supplements}

Supplementing expressions add parenthetical information that is secondary to the main claim being made. The bolded elements in the following example from Potts (2005: 13) illustrate two kinds of supplements to DP-(a) NOMINAL APPOSITIONS and (b) SUPPLEMENTARY RELATIVES. Following Potts, I will use the term ANCHOR to refer to the phrase that the supplement attaches to and adds information about.

(34) a. Ames, the former spy, is now behind bars.

b. Ames, who stole from the FBI, is now behind bars.

Also following Potts (2005), we can make the following observations about supplementary meaning. First, the anchor and its supplement compose to form a proposition. For example, in (34b), Ames and 'who stole from the FBI' compose to form the proposition Ames stole from the FBI. Secondly, the composition of this proposition is semantically detached from the rest of the composition process. This independence of the supplement proposition's meaning from the main (at-issue) content of the utterance is two-sided. On the one hand, the composition of the anchor and supplement occurs in isolation, meaning that it cannot make reference to semantic objects apart from the anchor and supplement themselves. On the other hand, once the supplementing proposition is composed, its meaning takes widest scope as a speaker-oriented commitment, and cannot affect the surrounding composition.

\subsection{Nominal Supplements to Quantificational DPs}

When supplementing material anchors to quantificational DPs, we immediately gain evidence as to the type of the DP in question. Consider (35), which is pragmatically odd, given the knowledge that John and Mary are common names.

(35) Two students, John and Mary, had unusual names.

If 'two students' were interpreted as a generalized quantifier, there would be no way to capture the oddness of (35). Let's see why. First, we have to ask what happens when the GQ meaning composes with 'John and Mary', which denotes a plurality. 
Even if we supposed that this composition were licensed (say, by type-shifting the plurality to a property using Montague's BE), we would just derive a weak meaning of Two students are John and Mary as the supplement proposition. But crucially, there is nothing odd about two students being John and Mary and two students having unusual names. Yet, the sentence cannot have this weak meaning.

On the other hand, if 'two students' gets a choice-functional reading, the composition proceeds without a hitch and the oddness of the sentence is captured. Suppose that in logical form, the subject contains a choice function variable $f_{7}$ which composes with the meaning 'two students' to produce a particular plurality of two students. In this case, the supplementing proposition will be that those two students picked out by $\mathrm{f}_{7}$ are John and Mary, and the at-issue meaning will be that those same two students have unusual names. This fixing of the two students across the two propositions comes for free on the assumption that choice function variables are free variables bound once at the level of discourse, following Kratzer (1998, 2003).

Since (35) only allows a choice-functional interpretation of the subject, and in particular lacks the meaning predicted if the subject were a GQ, we can use this sentence frame to test whether other quantifiers have choice-functional interpretations. For example, the fact that 'few students' in (36) is unable to anchor a nominal apposition indicates that 'few students' cannot be interpreted as type e.

(36) * Few students, John and Mary, had common names.

More generally, we can hypothesize that even if no other interpretation is possible, a GQ is still unable to stand as anchor to a nominal apposition. If there were a convincing exception to this generalization, it would involve a sentence where the GQ could be shown to be evaluated twice and witnessed by two different sets of individuals - once in the supplement, and once in the at-issue dimension. I know of no data that suggest such an option is ever available. Consider that even to the marginal degree that (36) is interpretable, the meaning still requires that we identify John and Mary rather than anyone else as the few students who have common names.

In (37), I test a range of quantifiers on their ability to host nominal appositions. Once again, the pattern that emerges is that the witnessable quantifiers- the somes and mosts-behave as a class distinctly from the non-witnessable ones-the fews. We have a natural explanation for these facts if all the witnessable quantifiers and only the witnessable quantifiers give rise to type-e nominals. ${ }^{13}$

13 Note that as with the equatives, the use of a partitive supports the felicity of the mosts as type e. Here, we need to be careful to ensure that the supplement isn't attaching to the nominal inside the partitive, in this case 'my students'. While this is a possible syntactic parse, the meaning would be unnatural; the claim that my students are "the ones who wanted to pass" is odd without a contrasting set in the context. We can also note that the partitive is not strictly necessary. With the exception of half, we get the same split in the frame " students, namely the ones who wanted to pass, came on time." 

of my students, (namely) the ones who wanted to pass, came on time.

$\left\{\begin{array}{c}\text { Some } \mid \text { Ten } \mid \text { Many } \mid \text { Several } \mid \text { A few } \\ \text { Most } \mid \text { More than ten } \mid \text { Exactly ten } \mid \text { Half } \\ \text { * None } \mid \text { ?? Few } \mid \text { ??Not many } \mid \text { ??Less than 20 }\end{array}\right\}$

One may ask why all is unnatural in the frame above, despite being witnessable. Again, this appears to be a problem with the meaning conveyed rather than with the types involved. The supplement 'the ones who wanted to pass' inherently picks out a subset of some group, and so is not a good characterization of all of the students. However, we can show that all does license supplements with the following:

(38) All contestants qualified to enter the next round, (namely) John, Mary, Sue and Bill, should now proceed to the stage.

\subsection{Relative Clause Supplements to Quantificational DPs}

Relative clause (RC) supplements, also known as NON-RESTRICTIVE or APPOSITIVE relative clauses, add further support for the emerging pattern. As with nominal appositions, RC supplements are incapable of attaching to non-witnessable DPs like 'few students'. The core data are as follows: ${ }^{14}$ congressmen, who incidentally are very junior, admire Kennedy.

$$
\left\{\begin{array}{c}
\text { Some } \mid \text { Ten } \mid \text { Many } \mid \text { Several } \mid \text { A few } \\
\text { Most } \mid \text { More than ten } \mid \text { Exactly ten } \mid \text { At least ten } \\
* \text { Few } \mid * \text { Not many } \mid * \text { Hardly any } \mid \text { ?? Less than ten }
\end{array}\right\}
$$

The basic explanation for these facts is the same as before. Like nominal appositions, $\mathrm{RC}$ supplements can only attach to individual-denoting expressions. However in this case, it's less clear what is driving the restriction. At least as far as the types are concerned, there seems to be no incompatibility between a GQ-denoting anchor and a property-denoting relative clause. But the data show us clearly that such a representation is illicit. Beyond the badness of the "fews", we see that none of the acceptable quantifiers in (39) allow GQ readings either. For example, the sentence with some can't mean just that some congressmen are very junior and some congressmen admire Kennedy. The two sets must coincide.

Whatever its source is, a ban on non-individual-denoting anchors is commonly assumed to be in effect, and is often relied upon to do important work. For example,

14 The supplementing adverb incidentally ensures that the relative clause is non-restrictive; see Emonds (1979: 64) and Potts (2005: §4.7) for discussion. Without the adverb, the judgments of infelicity depend solely on the comma intonation, and are less robust. If the pauses are missing too, or are overlooked, the clause can be interpreted as restricting the NP congressmen, giving the meaning 'Few junior congressmen admire Kennedy.' 
Witnessable quantifiers license type-e meaning

Karttunen (1969: §1.1) observes that a non-restrictive relative disambiguates to a specific reading of an otherwise ambiguous indefinite anchor, as in (40). Similarly, Heycock \& Kroch (1999: 374) show that predicative DPs, as in the object of the small clause in (41), resist non-restrictive RCs. See Sells (1985), Potts (2002) and Del Gobbo (2003: 152) for further discussion, and arguments that even non-nominal anchors must be able to denote type e.

(40) Bill didn't see a misprint, which I had made on purpose.

(41) *I consider Rita the duty nurse, who is very efficient.

\section{Remaining Issues}

The evidence from CT, equatives, and supplements all points in the same direction: all and only witnessable quantifiers permit type-e interpretation. If the way these quantificational DPs denote individuals is via choice function semantics, then we reach the conclusion that more quantifiers have choice-functional readings than traditionally thought. On the other hand, if some or all of these DPs denote individuals via some other mechanism, then we are left to explain what that mechanism is.

If we opt for choice functions, several challenges lie ahead. First, we have to ask why quantifiers like most fail to exhibit the exceptional wide-scope readings expected if they are choice-functional on theories like Reinhart 1997 and Winter 1997. In fact, most can scope out of islands, as observed by Abusch (1994: 118) and Endriss (2009: 249). This ability, which distinguishes most from few, as shown in (42), could be construed as support for the present analysis. The problem is that most can only take so-called distributive wide-scope, and never the collective wide-scope that we expect on the choice-functional account. That is, most in (43) is unlike three, in only allowing narrow scope (ignoring a dispreferred distributive reading); the sentence can't mean that our safety depends on a particular majority supporting her. In short, the scope facts are partially at odds with the diagnostics discussed above. This inconsistency demands further analysis, and simultaneously calls into question the role of wide-scope as the de facto test for quantifier type.

(42) If $\{$ most $\mid \#$ few $\}$ people were president, they would find it stressful.

(43) If $\{$ three $\mid$ most $\mid$ few $\}$ people support her, we're safe.

Finally, if we accept that witnessable quantifiers need choice-functional denotations (in addition to their standard quantificational denotations), the task remains of establishing what the right denotations are. This project is especially challenging in the case of non-monotonic witnessable quantifiers like exactly three, where it is unclear how a choice-functional account would derive the "no more than three" upper bound. I leave this task to future work. 
Constant

\section{References}

Abusch, Dorit. 1994. The scope of indefinites. Natural Language Semantics 2(2). 83-135. doi:10.1007/BF01250400.

Barwise, Jon \& Robin Cooper. 1981. Generalized quantifiers and natural language. Linguistics and Philosophy 4(2). 159-219. doi:10.1007/BF00350139.

Büring, Daniel. 1997. The great scope inversion conspiracy. Linguistics and Philosophy 20(2). 175-194. doi:10.1023/A:1005397026866.

Büring, Daniel. 2003. On D-trees, beans, and B-accents. Linguistics and Philosophy 26(5). 511-545. doi:10.1023/A:1025887707652.

Constant, Noah. in prep. Contrastive topic: Meanings and realizations. Amherst: University of Massachusetts PhD dissertation.

Del Gobbo, Francesca. 2003. Appositives at the interface. Irvine: University of California $\mathrm{PhD}$ dissertation.

Emonds, Joseph. 1979. Appositive relatives have no properties. Linguistic Inquiry 10(2). 211-243. http://www.jstor.org/stable/4178107.

Endriss, Cornelia. 2009. Quantificational Topics: A Scopal Treatment of Exceptional Wide Scope Phenomena. Springer. doi:10.1007/978-90-481-2303-2.

von Fintel, Kai. 1994. Restrictions on quantifier domains. Amherst: University of Massachusetts PhD dissertation.

Heim, Irene. 1990. E-type pronouns and donkey anaphora. Linguistics and Philosophy 13(2). 137-177. doi:10.1007/BF00630732.

Heycock, Caroline \& Anthony Kroch. 1999. Pseudocleft connectedness: Implications for the LF interface level. Linguistic Inquiry 30(3). 365-397. doi:10.1162/002438999554110.

Horn, Laurence R. 1972. On the semantic properties of logical operators in English. Los Angeles: University of California $\mathrm{PhD}$ dissertation.

Horn, Laurence R. 2006. The border wars: A neo-Gricean perspective. In Klaus von Heusinger \& Ken Turner (eds.), Where Semantics Meets Pragmatics, 21-48. Elsevier.

Kamp, Hans. 1971. Formal properties of 'now'. Theoria 37. 227-273. doi: 10.1111/j.1755-2567.1971.tb00071.x.

Karttunen, Lauri. 1969. Discourse referents. In 1969 Conference on Computational Linguistics, 1-38. Association for Computational Linguistics. doi:10.3115/ 990403.990490.

Kratzer, Angelika. 1998. Scope or pseudo-scope: Are there wide-scope indefinites? In Susan Rothstein (ed.), Events in Grammar, 163-196. Dordrecht: Kluwer.

Kratzer, Angelika. 2003. A note on choice functions in context. Ms. University of Massachusetts, Amherst. http://semanticsarchive.net/Archive/zIyNTMxZ/.

Kripke, Saul. 1959. A completeness theorem in modal logic. Journal of Symbolic 
Witnessable quantifiers license type-e meaning

Logic 24. 1-14. doi:10.2307/2964568.

Kripke, Saul. 1963. Semantical analysis of modal logic I: Normal modal propositional calculi. Zeitschrift für mathematische Logik und Grundlagen der Mathematik 9. 67-96. doi:10.1002/malq.19630090502.

Landman, Fred. 1989. Groups, I. Linguistics and Philosophy 12(5). 559-605. doi:10.1007/BF00627774.

Link, Godehard. 1983. The logical analysis of plurals and mass terms: A latticetheoretical approach. In Rainer Bäuerle, Christoph Schwarze \& Arnim von Stechow (eds.), Meaning, Use and the Interpretation of Language, 303-23. Walter de Gruyter. doi:10.1515/9783110852820.302.

Mikkelsen, Line. 2004. Specifying who: On the structure meaning and use of specificational copular clauses. Santa Cruz: University of California $\mathrm{PhD}$ dissertation.

Montague, Richard. 1973. The proper treatment of quantification in ordinary English. In K. Jaakko J. Hintikka, Julius M. E. Moravcsik \& Patrick Suppes (eds.), Approaches to Natural Language: 1970 Stanford Workshop on Grammar and Semantics, 221-42. Dordrecht: D. Reidel.

Partee, Barbara H. 1973. Some structural analogies between tenses and pronouns in English. Journal of Philosophy 70(18). 601-609. doi:10.2307/2025024.

Partee, Barbara H. 1987. Noun phrase interpretation and type-shifting principles. In Jeroen A. G. Groenendijk, Dick De Jongh \& Martin J. B. Stokhof (eds.), Studies in Discourse Representation Theory and the Theory of Generalized Quantifiers, 115-143. Dordrecht: Foris.

Potts, Christopher. 2002. The lexical semantics of parenthetical-as and appositivewhich. Syntax 5(1). 55-88. doi:10.1111/1467-9612.00047.

Potts, Christopher. 2005. The Logic of Conventional Implicatures. Oxford University Press, USA. doi:10.1093/acprof:oso/9780199273829.001.0001.

Reinhart, Tanya. 1997. Quantifier scope: How labor is divided between QR and choice functions. Linguistics and Philosophy 20(4). 335-397. doi:10.1023/A: 1005349801431.

Roberts, Craige. 1996. Information structure in discourse: Towards an integrated formal theory of pragmatics. Ohio State University Working Papers in Linguistics 49 (Papers in Semantics) 91-136.

Rooth, Mats. 1985. Association with focus. Amherst: University of Massachusetts $\mathrm{PhD}$ dissertation.

Rooth, Mats. 2005. Topic accents on quantifiers. In Gregory N. Carlson \& Francis Jeffry Pelletier (eds.), Reference and Quantification: The Partee Effect, Stanford: CSLI Publications.

Schwarzschild, Roger. 1996. Pluralities. Kluwer Academic Publishers.

Sells, Peter. 1985. Restrictive and Non-Restrictive Modification. Stanford University: 
Center for the Study of Language and Information.

Silverman, Kim, Mary Beckman, John Pitrelli, Mari Ostendorf, Colin Wightman, Patti Price, Janet Pierrehumbert \& Julia Hirschberg. 1992. ToBI: a standard for labeling English prosody. In Second International Conference on Spoken Language Processing, vol. 2, 867-870. Banff, Canada.

Steedman, Mark. 2008. Information-structural semantics for English intonation. In Chungmin Lee, Matthew Gordon \& Daniel Büring (eds.), Topic and Focus: Cross-Linguistic Perspectives on Meaning and Intonation, 245-264. Dordrecht: Springer. doi:10.1007/978-1-4020-4796-1_13.

Szabolcsi, Anna. 1995. On modes of operation. In Paul Dekker \& Martin Stokhof (eds.), 10th Amsterdam Colloquium, University of Amsterdam.

Szabolcsi, Anna. 1997. Strategies for scope taking. In Anna Szabolcsi (ed.), Ways of Scope Taking, 109-154. Dordrecht: Kluwer.

Tomioka, Satoshi. 2010. A scope theory of contrastive topics. Iberia 2(1). 113-130.

Wagner, Michael. 2008. A compositional analysis of contrastive topics. In Muhammad Abdurrahman, Anisa Schardl \& Martin Walkow (eds.), North East Linguistic Society (NELS) 38, University of Massachusetts, Amherst: Graduate Linguistics Student Association (GLSA).

Wagner, Michael. 2012. Contrastive topics decomposed. Semantics and Pragmatics 5(8). 1-54. doi:10.3765/sp.5.8.

Winter, Yoad. 1997. Choice functions and the scopal semantics of indefinites. Linguistics and Philosophy 20(4). 399-467. doi:10.1023/A:1005354323136.

Noah Constant

Department of Linguistics

University of Massachusetts

Amherst, MA 01003-9274

constant@linguist.umass.edu 